\title{
Love is in the hair: arginine methylation of human hair proteins as novel cardiovascular biomarkers
}

\author{
Alistair James Marsden ${ }^{1}$. David R. J. Riley ${ }^{1}$ Stefan Birkett ${ }^{2,3} \cdot$ Quentin Rodriguez-Barucg $^{1}$ - Barbara-ann Guinn ${ }^{1}$. \\ Sean Carroll ${ }^{2} \cdot$ Lee Ingle $^{2} \cdot$ Thozhukat Sathyapalan $^{4} \cdot$ Pedro Beltran-Alvarez $^{1}$ (D)
}

Received: 27 January 2021 / Accepted: 17 June 2021 / Published online: 28 June 2021

(c) The Author(s) 2021

\begin{abstract}
Cardiovascular disease is the major cause of death worldwide. Extensive cardiovascular biomarkers are available using blood tests but very few, if any, investigations have described non-invasive tests for cardiovascular biomarkers based on readily available hair samples. Here we show, first, that human hair proteins are post-translationally modified by arginine methylation (ArgMe). Using western blot, proteomic data mining and mass spectrometry, we identify several ArgMe events in hair proteins and we show that keratin-83 is extensively modified by ArgMe in the human hair. Second, using a preliminary cohort $(n=18)$ of heterogenous healthy donors, we show that the levels of protein ArgMe in hair correlate with serum concentrations of a well-established cardiovascular biomarker, asymmetric dimethylarginine (ADMA). Compared to blood collection, hair sampling is cheaper, simpler, requires minimal training and carries less health and safety and ethical risks. For these reasons, developing the potential of hair protein ArgMe as clinically useful cardiovascular biomarkers through further research could be useful in future prevention and diagnosis of cardiovascular disease.
\end{abstract}

Keywords Arginine methylation (ArgMe) - Asymmetric dimethylarginine (ADMA) - Biomarker · Cardiovascular disease (CVD) · Hair · Post-translational modifications (PTM) · Protein

\section{Introduction}

Cardiovascular disease (CVD) is still the leading cause of death in industrialised countries and is associated with enormous public health and economic costs (Virani et al. 2020). Globally, the proportion of deaths due to CVD is growing (Roth et al. 2019). Many biomarkers of cardiovascular health and disease have been developed, including B-type natriuretic peptide, markers of oxidative stress, inflammatory

Handling editor: D. Tsikas.

Pedro Beltran-Alvarez

p.beltran-alvarez@hull.ac.uk

1 Department of Biomedical Sciences, University of Hull, Cottingham Rd, Hull HU6 7RX, UK

2 Department of Sport, Health and Exercise Science, University of Hull, Hull, UK

3 School of Sport and Health Sciences, University of Central Lancashire, Preston, UK

4 Academic Endocrinology, Diabetes and Metabolism, Hull York Medical School, University of Hull, Hull, UK mediators and metabolic biomarkers (Hirata et al. 2020), among others (Adamcova and Šimko 2018). These measurements are almost always done on serum and therefore require invasive procedures and specialised personnel, with variable assay costs.

In contrast, over the past few years, hair monitoring has gained visibility as a possible testing substrate for many diagnostic and forensic applications (Adeola et al. 2018). Hair collection is simple, non-invasive and can be performed by minimally trained personnel. Hair samples can be stored long-term without the need for laboratory space or equipment and, compared to blood samples, carry no, or very little, health and safety risks for the experimenter and/or the environment.

Hair consists mainly of proteins (Chen and Yu 2020). Protein post-translational modifications (PTMs) are critical players in protein biochemistry, can change protein structure, activity, localization and interactions (Onwuli and Beltran-Alvarez, 2016), and can modify proteins in many tissues, including hair (Adav et al. 2018). In our laboratory, we are studying a particular PTM known as arginine methylation (ArgMe). Protein ArgMe consists of the transfer of a methyl group $\left(\mathrm{CH}_{3}\right)$ from 
S-adenosyl-L-methionine to the side chain guanidino nitrogen of arginine, in an enzymatic reaction catalysed by protein arginine methyltransferases (PRMTs), (Samuel et al. 2021). The addition of a $\mathrm{CH}_{3}$ group removes a potential hydrogen bond donor from the recipient arginine and produces bulkier and more hydrophobic methylarginine residues. In humans, there are three types of PRMTs that catalyse ArgMe, each responsible for a different ArgMe end-product. Type I and II PRMTs catalyse Arg monomethylation followed by, respectively, asymmetric and symmetric dimethylation. Type III PRMTs are defined as producing monomethylarginine residues only (Jarrold and Davies 2019). Type I PRMTs include PRMT1, $-2,-3,-4,-6$ and -8 . PRMT5 and -9 are type II PRMTs and PRMT7 is accepted as the only type III PRMT (Zurita-Lopez et al. 2012).

The degradation of proteins modified by ArgMe leads to the proteolytic products $\mathrm{N}^{\mathrm{G}}$-monomethyl-L-arginine (MMA), $\mathrm{N}^{\mathrm{G}}, \mathrm{N}^{\mathrm{G}}$-dimethyl-L-arginine (asymmetric dimethylarginine, ADMA) and $\mathrm{N}^{\mathrm{G}}, \mathrm{N}^{\prime} \mathrm{G}$-dimethyl-L-arginine (symmetric dimethylarginine, SDMA), and the levels of these circulating methylarginine metabolites are thought to correlate with the cellular concentration of proteins modified by ArgMe (Bollenbach et al. 2019; Post et al. 2021). These metabolites exercise a range of functions when released into the circulation, notably related to nitric oxide synthase inhibition. As such, high levels of methylarginine metabolites, such as ADMA, in serum are associated with endothelial dysfunction, provide well-known prognostic markers for cardiovascular risk and mortality (Jarzebska et al. 2019; Mangoni et al. 2021; Tsikas 2020) and correlate with cardiorespiratory dysfunction (Böger et al. 1997; Krempl et al. 2005; Leong et al. 2008; Meinitzer et al. 2007; Surdacki et al. 1999; Tajti et al. 2018; Yoo and Lee 2001; Zinellu et al. 2018).

To the best of our knowledge, ArgMe of hair proteins has not previously been reported. Here, we hypothesised that hair proteins are modified by ArgMe and we aimed to investigate any correlation between hair protein ArgMe and serum ADMA. This may provide a cardiovascular marker based on hair sampling, which provides a longer time of reference and is less susceptible to short-time diurnal or biological variability than blood or urine sampling. Given the impending perfect storm of climate change and a predicted increase in CVD over the next few decades (Watts et al. 2021), the identification of valid and reliable cardiovascular biomarkers in hair samples has the potential to enhance primary care, early diagnosis, prevention of disease development and management of CVD.

\section{Materials and methods}

\section{Hair samples}

Hair samples from healthy volunteers were collected from the posterior side of their head and as close as possible to the scalp within the context of University of Hull Faculty of Health Sciences ethically approved project, reference FHS57 and a Hull York Medical School ethically approved clinical study, reference 17_11. Inclusion criteria for the subjects were age (18-65 years), non-clinically obese BMI (between 19 and $29 \mathrm{~kg} / \mathrm{m}^{2}$ ), and completion of informed consent. An additional inclusion criterium was length of hair at the posterior side of the scalp ( $>5 \mathrm{~cm}$ ), this is the likely reason why all participants were female. Exclusion criteria were subjects who had bleached or dyed their hair in the 6 months prior to sample collection, concurrent disease, alcohol intake within $24 \mathrm{~h}$ of donation and pregnancy. Approximately 40 individual hairs were collected from each participant, alongside 2-5 mL blood through venepuncture. Blood was incubated at room temperature for $30 \mathrm{~min}$ in upright tubes to allow for blood clotting, and serum was then collected by centrifugation at $16,000 \mathrm{~g}$ for $20 \mathrm{~min}$. Serum and hair samples were stored at $-20^{\circ} \mathrm{C}$ until being analysed.

\section{Protein lysis and western blot for hair protein ArgMe measurements}

The closest centimetres to scalp of hair strands were manually minced into small (approximately $1 \mathrm{~mm}$ ) fragments and proteins from at least $5 \mathrm{mg}$ hair were extracted into $300 \mu \mathrm{l}$ of buffer according to the Minute protein extraction kit for hair and nails (Invent Biotechnologies), which includes incubation in $0.5 \%$ SDS and $10 \% \beta$-mercaptoethanol at $55{ }^{\circ} \mathrm{C}$ for $>24 \mathrm{~h}$. Protein lysates were separated through 10-12\% SDS-PAGE along a protein marker (\#26619, Thermofisher) and proteins transferred to PVDF membranes (GE Healthcare). We used two validated $\alpha$-ArgMe antibodies (\#8015 and \#8711, Cell Signalling Technologies) and an $\alpha$-keratin-83 antibody (ab174272, Abcam) at 1:1000 dilutions in 5\% non-fat milk. Quantification of protein band intensity and the overlap of ArgMe and keratin-83 intensities were done using ImageJ. All samples were electrophoresed down a parallel gel, which was silver-stained for total protein normalisation. Inter-gel quantifications were done with the aid of internal controls.

\section{ELISA for ADMA measurements}

ADMA levels were measured in serum, in duplicate, using a commercial ELISA kit (Abcam, \#ab213972). Synthetic 
ADMA standards for calibration were purchased from Merck. Raw calibration measurements and a four-parameter logistic curve fitting are shown in Supp. Figure 1.

\section{MaxQuant analysis of protein ArgMe}

The bioinformatic analysis was completed following published protocols (Onwuli et al. 2017). Briefly, proteomic raw data from PXD007224 (Adav et al. 2018) and PXD016169 (Plott et al. 2020) were downloaded from the PRIDE proteomics database and mined for protein ArgMe using MaxQuant (v1.6.14.0 and v1.6.17.0 for PXD007224 and PXD016169, respectively). ArgMe was set as a variable modification together with Met oxidation and N-terminal protein acetylation. Cys carbamidomethylation was set as a fixed modification. MaxQuant parameters were set as default in qualitative searches against the human proteome (GRCh38 and UP000005640, 20610 proteins, March 2021 for PXD007224 and PXD016169, respectively).

\section{Mass spectrometry analysis of keratin-83}

Hair lysates were resolved by SDS-PAGE and the gel stained using GelCode blue stain reagent (Thermo). The band putatively corresponding to keratin-83 at around $60 \mathrm{kDa}$ was excised and destained. Proteins therein were reduced, alkylated and trypsinised (Pierce) overnight at $37{ }^{\circ} \mathrm{C}$. Peptides were desalted and loaded onto a $50 \mathrm{~cm}$ EasyNano PepMap column driven by a Water mClass UPLC, with elution over $1 \mathrm{~h}$ onto an Orbitrap Fusion Tribrid mass spectrometer operated in data-dependent acquisition (DDA) mode. Resulting spectra were searched using Mascot against the human subset of the UniProt database. Oxidation of Met and mono- and dimethylation of Arg were specified as variable modifications. Trypsin specificity was set as semi- and missed cleavages were set to a maximum of four. Scaffold PTM (version 5.0.1, Proteome Software) was then used to annotate PTM sites derived from MS/MS sequencing results.

\section{Results}

\section{Hair proteins are modified by ArgMe}

To gain an understanding of the scope of protein ArgMe in human hair, we searched proteomics datasets of the hair proteome from healthy adult individuals (PXD007224 and PXD016169 from Adav et al. (2018) and Plott et al. (2020), respectively) for ArgMe. Using our recently published proteomics workflow (Onwuli et al., 2017), we identified tens of ArgMe sites in hair proteins (Supp. Tables 1 and 2). We counted $4 \mathrm{ArgMe}$ sites in 4 proteins that were found in both the PXD007224 and the PXD016169 datasets (Table 1), including on keratin-83, one of the most abundant proteins in hair (Moll et al. 2008).

To provide direct evidence that hair proteins are modified by ArgMe, we collected hair samples from healthy participants and searched for hair protein ArgMe using western blotting. We routinely observed several protein bands in the range of $55-70 \mathrm{kDa}$ recognised by antibodies specific for mono-ArgMe (Fig. 1).

We hypothesised that one of the major bands recognised by the $\alpha$-ArgMe antibodies may correspond to keratin- 83 and an antibody against keratin- 83 appeared to recognise the same protein band as the $\alpha-A r g M e$ antibody at $55-70 \mathrm{kDa}$ (Fig. 1 and Supp. Figures 2 and 3). The keratin-83 antibody recognised other bands below $35 \mathrm{kDa}$, which may correspond to protein degradation under the harsh conditions used for protein extraction from hair (Navone and Speight 2018). We then isolated keratin-83 from human hair lysates and analysed the protein by mass spectrometry. We found that keratin-83 was extensively modified by ArgMe (Fig. 1D, Supp. Figure 4 and Supp. Table 3). This is the first report of ArgMe in hair proteins.

\section{Levels of hair protein ArgMe correlate with serum ADMA concentrations}

To provide proof of concept that levels of hair protein ArgMe may correlate with serum ADMA concentrations, we recruited 18 healthy volunteers (see Table 2 for clinical data) for collection of hair and blood samples in a small clinical study. First, we examined whether ArgMe
Table 1 ArgMe sites identified in both PXD007224 and PXD016169

\begin{tabular}{lllll}
\hline Gene name & Protein name & $\begin{array}{l}\text { Molecular } \\
\text { weight }(\mathrm{kDa})\end{array}$ & Mono-ArgMe sites & Di-ArgMe sites \\
\hline KRT33A & Keratin, type I cuticular Ha3-I & 45.9 & 173 & Not in common \\
KRT86 & Keratin, type II cuticular Hb6 & 53.5 & 21 & Not in common \\
KRT83 & Keratin, type II cuticular Hb3 & 54.2 & 26 & Not in common \\
HDAC5 & Histone deacetylase 5 & 122.0 & Not in common & 151 \\
\hline
\end{tabular}


A
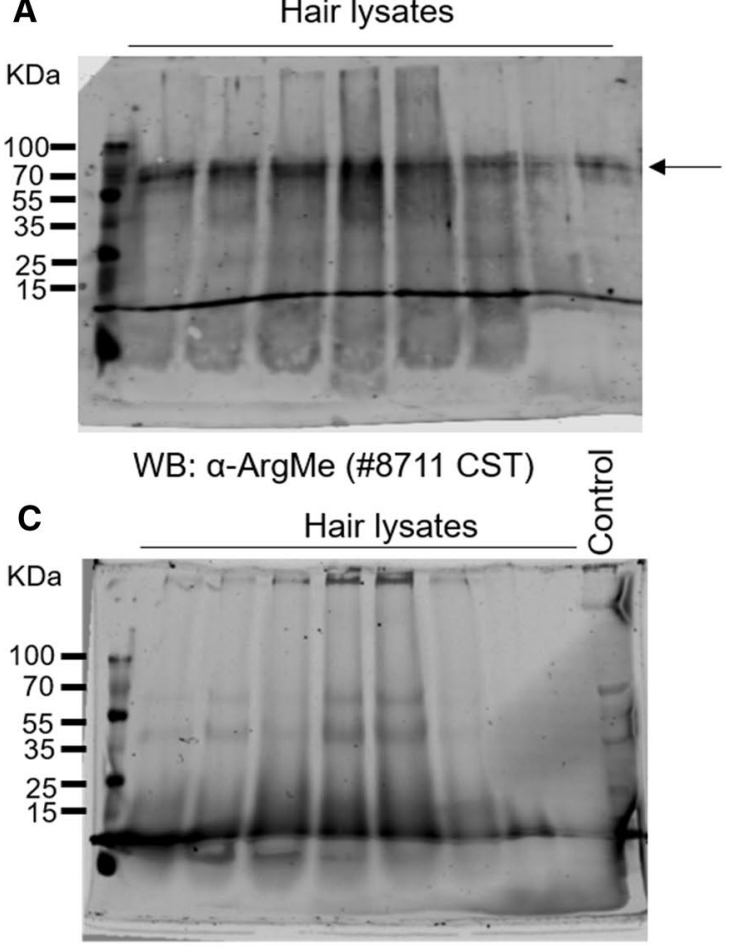

B

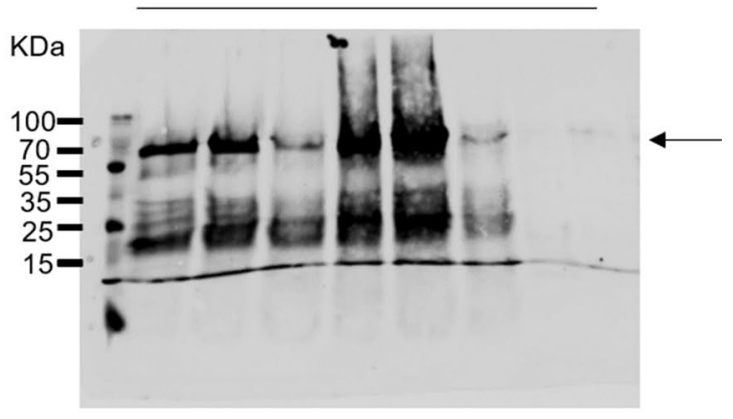

WB: keratin-83
D

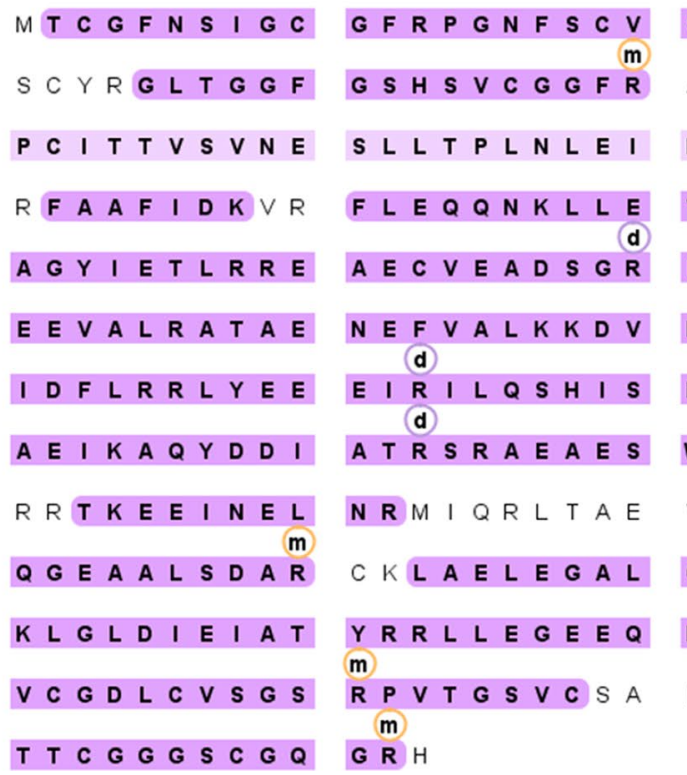

Fig. 1 A Western blot showing detection of hair protein ArgMe from 8 healthy volunteers. An antibody targeting protein ArgMe recognised a major protein band between the 55 and $70 \mathrm{kDa}$ markers (indicated by the arrow). B Same participants and same membrane as in (A) blotted using an antibody targeting keratin-83, a universal hair protein of expected MW of 54.2 KDa and detected between the 55 and $70 \mathrm{kDa}$ markers (arrow). See Supp. Figure 2 for a higher exposure and Supp. Figure 3 for the overlap of the ArgMe and the

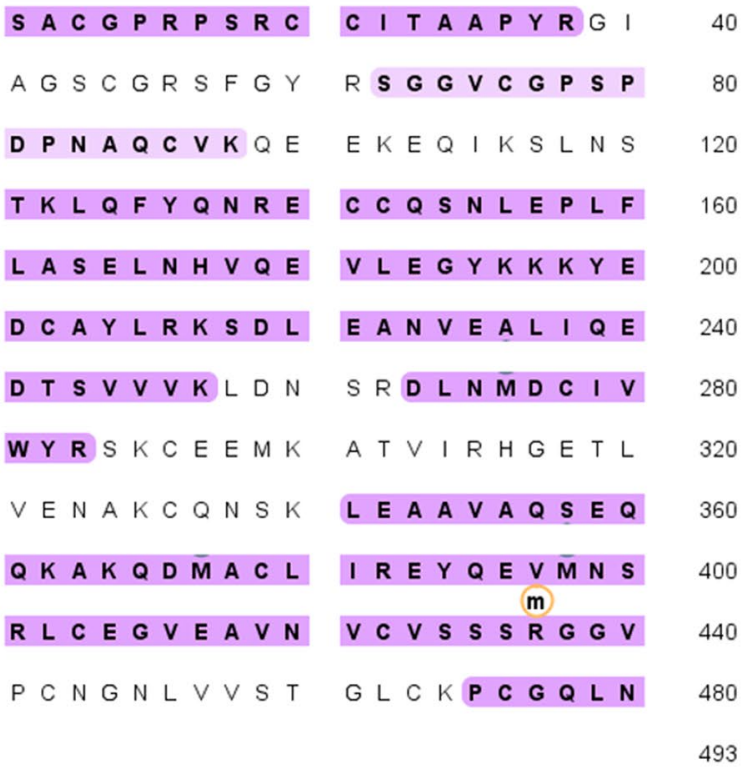

keratin-83 panels. C. Silver staining of a gel loaded with the same samples as in (A) and (B). Twenty $\mu \mathrm{g}$ of proteins were loaded in the control lane for comparison with hair protein loading. D. Sequence coverage of keratin-83 mass spectrometry analysis (shaded residues, $81 \%$ of all keratin- 83 sequence). Arginine residues found to be modified by mono- and di-ArgMe are identified with $m$ and $d$ labels, respectively, and include: R60, R180, R253, R293, R370, R437, R451 and R492 
Table 2 Clinical measurements of participants in our clinical study, sorted by ascending serum ADMA concentration. All participants in the clinical study were female

\begin{tabular}{llllllll}
\hline Participant No & $\begin{array}{l}\text { Serum } \\
\text { ADMA } \\
(\mu \mathrm{M})\end{array}$ & Age $(\mathrm{y})$ & Height $(\mathrm{cm})$ & Weight $(\mathrm{kg})$ & BP $(\mathrm{mmHg})$ & Pulse $(\mathrm{bpm})$ & BMI $\left(\mathrm{kg} / \mathrm{m}^{2}\right)$ \\
\hline 1 & 0.349 & 18 & 167 & 55 & $116 / 77$ & 90 & 19 \\
2 & 0.396 & 42 & 163 & 65 & $133 / 86$ & 75 & 25 \\
3 & 0.419 & 46 & 168 & 69 & $135 / 84$ & 71 & 25 \\
4 & 0.432 & 19 & 158 & 65 & $123 / 82$ & 72 & 26 \\
5 & 0.434 & 44 & 163 & 79 & $148 / 74$ & 68 & 29 \\
6 & 0.434 & 23 & 160 & 73 & $116 / 75$ & 64 & 29 \\
7 & 0.436 & 60 & 166 & 60 & $143 / 55$ & 63 & 23 \\
8 & 0.437 & 32 & 170 & 57 & $110 / 83$ & 59 & 19 \\
9 & 0.438 & 38 & 170 & 80 & $111 / 79$ & 71 & 28 \\
10 & 0.438 & 28 & 178 & 90 & $128 / 86$ & 70 & 29 \\
11 & 0.443 & 51 & 165 & 67 & $99 / 76$ & 68 & 24 \\
12 & 0.446 & 52 & 162 & 61 & $121 / 82$ & 71 & 23 \\
13 & 0.448 & 58 & 167 & 80 & $131 / 86$ & 75 & 29 \\
14 & 0.461 & 55 & 156 & 70 & $147 / 60$ & 64 & 29 \\
15 & 0.464 & 44 & 175 & 72 & $110 / 63$ & 70 & 23 \\
16 & 0.465 & 55 & 168 & 69 & $121 / 63$ & 73 & 23 \\
17 & 0.468 & 50 & 170 & 82 & $150 / 74$ & 71 & 29 \\
18 & 0.484 & 19 & 165 & 65 & $125 / 85$ & 75 & 24 \\
\hline & & & & & & & \\
\hline
\end{tabular}

was a stable mark on hair proteins. We ran western blots using hair protein lysates from the closest (Fig. 2A) and the 3rd closest (Fig. 2B) centimetres to the scalp of matched donors. We found that ArgMe marks were maintained on proteins at 55-70 kDa over what would correspond to a period of 2-3 months of hair growth.

We then measured ArgMe of hair proteins by quantitating the intensity of the bands corresponding to methylated proteins in the closest $\mathrm{cm}$ to the scalp and normalised them to total protein loading. We also measured serum ADMA concentrations and we found that all values were within the expected range for healthy adults, which has long been known to be in the hundreds of nM (Fleck et al. 2003; Zakrzewicz and Eickelberg 2009), (Table 2). We observed a positive correlation between the amount of protein ArgMe in the hair and the concentration of ADMA in the serum (Fig. 2C), as indicated by a Pearson coefficient of 0.5302 and a Spearman coefficient of 0.720 ( $p<0.05$ in both cases). There were no statistically significant correlations between the levels of hair protein ArgMe (or serum ADMA concentrations) and participant age, height, weight, BP or BMI.

Taken together, our data indicate that (1) protein modification by ArgMe occurs in hair proteins and (2) levels of hair protein ArgMe correlate with those of serum ADMA in healthy volunteers.

\section{Discussion}

Hair is an ideal surrogate tissue for biomarker discovery as it is easy to sample, has good patient compliance and few ethical issues. In this paper, we are first to report that human hair proteins are post-translationally modified by ArgMe, this is based on the recognition of hair proteins by two different antibodies specific for ArgMe, and on the analysis of mass spectrometry data. Furthermore, we propose that keratin-83 is one of the major proteins modified by ArgMe in the human hair. Within our preliminary, small cohort ( $n=18$ apparently healthy, but evidently heterogeneous donors), we show that the levels of protein ArgMe in hair correlate moderately with raised serum concentrations of a well-established cardiovascular biomarker, that is, ADMA.

Our findings complement the growing body of literature that has analysed the levels of the stress hormone cortisol in the hair as a biomarker of chronic stress, but here we make a direct link to CVD risk. The association between hair cortisol, chronic stress and CVD has been investigated and elevated hair cortisol levels have been found in patients with acute myocardial infarction (Pereg et al. 2011) and those at risk of CVD (Manenschijn et al. 2013). However, the relationship between chronic stress 


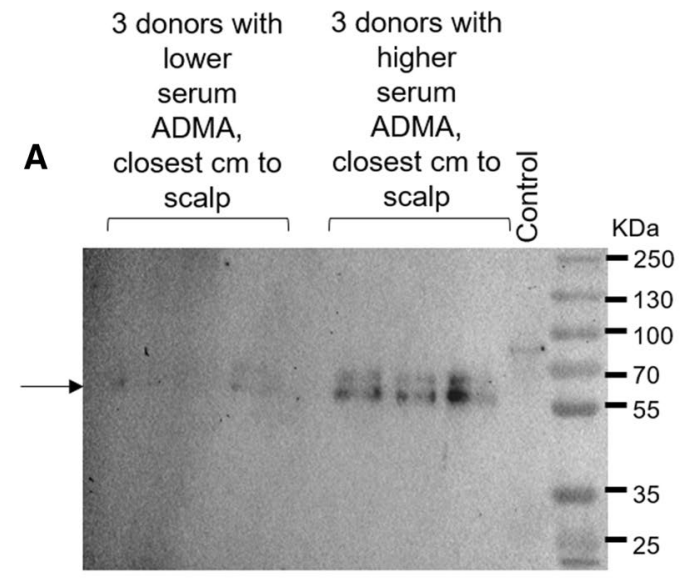

WB: $\alpha-A r g M e(\# 8015$ CST)

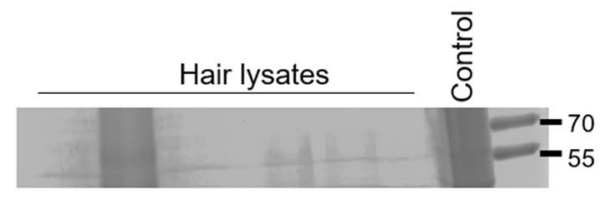

Gel staining

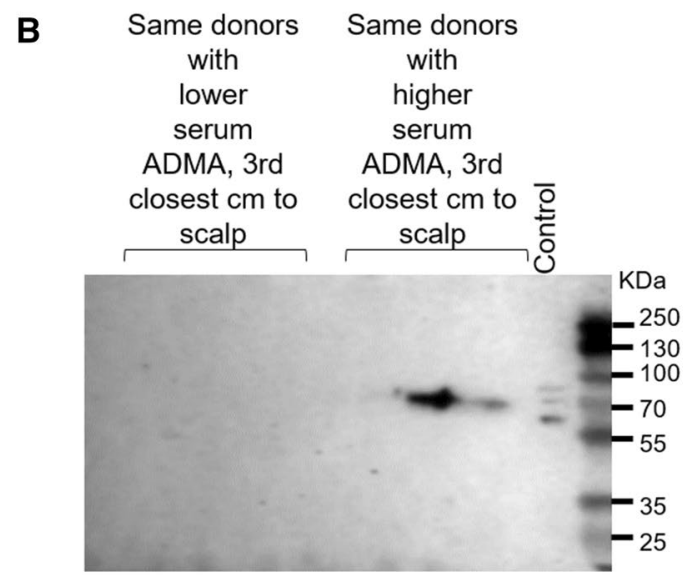

WB: $\alpha-A r g M e ~(\# 8015$ CST)

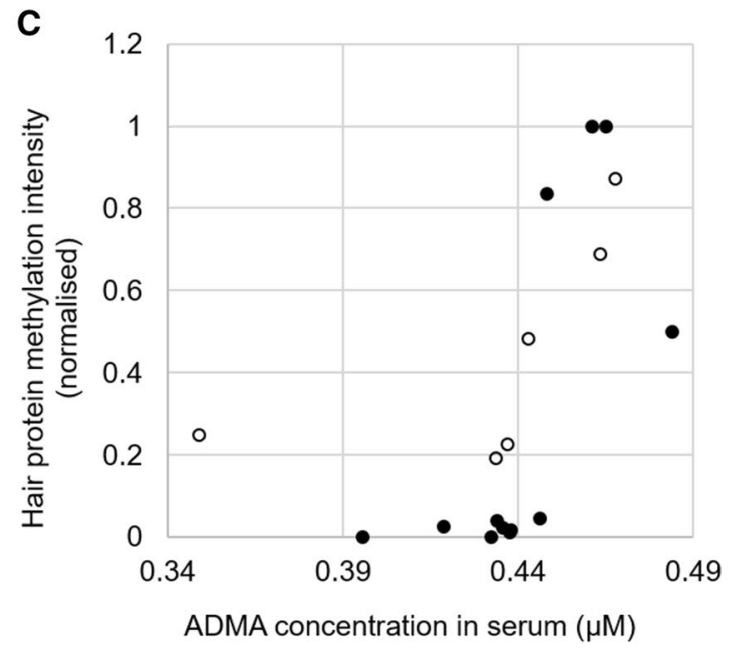

ADMA concentration in serum $(\mu \mathrm{M})$
Fig. 2 A Top, western blot showing increased protein ArgMe in hair proteins coming from the closest $\mathrm{cm}$ to the scalp of volunteers with $>0.44 \mu \mathrm{M}$ serum ADMA levels. Bottom, same samples ran on a parallel gel, stained as loading control. The second lane from the left appears overloaded but there was little ArgMe signal on that lane. B Same donors as in (A), but in this case the 3 rd closest centimetre to

and CVD is undoubtedly complex (Russell et al. 2012; Wester and van Rossum 2015), with stress negatively affecting traditional risk factors for CVD including hypertension, smoking, diabetes, obesity and physical inactivity (Iob and Steptoe 2019), and chronically elevated cortisol concentrations dysregulating lipid and glucose metabolism (Geer et al. 2014; Whitworth et al. 2005).

In contrast, the biology of methylarginine metabolites is considerably simpler and a direct link may be established between high levels of circulating ADMA and the risk for the scalp was analysed. C Plot showing a moderate positive correlation between the intensity of hair protein ArgMe and serum ADMA concentration, $n=18$ samples. The six samples shown in panel (A) are identified as empty circles in panel $(\mathbf{C})$. Pearson coefficient: $0.5302, p=0.024$. Spearman coefficient: $0.720, p=0.00075$

CVD through the inhibition of endothelial nitric oxide synthase (Banjarnahor et al. 2020; Bollenbach et al. 2020; Craig et al. 2021; Kayacelebi et al. 2015). In the present study, we have combined the convenience of using both hair samples and methylarginine biomarkers by developing a new assay that measures ArgMe in hair proteins. Given that (1) methylarginine metabolites, including ADMA, derive from the proteolysis of proteins carrying methylated Arg residues, (2) serum ADMA concentrations have been hypothesised to correlate with average ArgMe activity across the whole 
body in healthy volunteers (Bollenbach et al. 2019) and renal patients (Post et al. 2021) and (3) the hair at the back of the scalp grows at approx. $1 \mathrm{~cm}$ per month, levels of ArgMe of proteins in each $\mathrm{cm}$ of hair could reflect average monthly levels of PRMT activity in hair follicles. Tissue-specific PRMT activity has been associated with metabolic disease, obesity and diabetes (vanLieshout and Ljubicic 2019). PRMT expression is increased in the retina of diabetic rats (Chen et al. 2009) and in endothelial cells exposed to lowdensity lipoproteins (Böger et al. 2000; Jiang et al. 2006). It is tempting to speculate that PRMT activity in hair follicles may also increase with endothelial dysfunction.

This could at least partly explain our results, which show that the levels of hair protein ArgMe in the closest $\mathrm{cm}$ to the scalp correlate with serum ADMA concentrations, however, the molecular basis of this correlation is likely to be more complex. Methylarginine metabolites are generated upon the degradation of proteins with methylated arginines and eliminated mainly through renal excretion either unchanged (SDMA) or metabolised (MMA and ADMA, in the form of mono- and di-methylamine, respectively), (Said et al. 2019). The enzyme responsible for the hydrolysis of MMA and ADMA into mono- and di-methylamine (and citrulline) is dimethylarginine dimethylaminohydrolase (DDAH1), (Hu et al., 2011). Consistent with this, animal studies have shown that knocking down DDAH1 increases plasma ADMA concentrations (Rodionov et al. 2019), that DDAH1 knock-out leads to CVD (Leiper et al. 2007) and that DDAH1 overexpression protects from CVD (Dayoub et al. 2008; Jacobi et al. 2010). Also, gene variants in DDAH1 have been associated with CVD in patients (Hannemann et al. 2020). Therefore, this body of evidence suggests that the levels of expression and activity of DDAH1 are key players in the development of CVD through controlling ADMA clearance (Jarzebska et al. 2019). Furthermore, the metabolism of ADMA and SDMA can also include transamination into asymmetric or symmetrical $\alpha$-keto-dimethylguanidinovaleric acid, catalysed by alanine:glyoxylate aminotransferase 2 (AGXT2), and functional variants in AGXT2 may also be associated with CVD (Yoshino et al., 2014), presumably through increasing plasma ADMA concentrations.

Within this context, our work needs to be regarded as an observational study where the correlation between hair protein ArgMe and serum ADMA levels is made but we do not yet provide mechanistic insights to fully explain this correlation. Of note, the correlation between hair protein ArgMe and serum ADMA, albeit based on semi-quantitative western blot analyses, was the only statistically significant one, of those examined. Indeed, hair protein ArgMe or serum ADMA levels did not correlate with clinical parameters; as expected in a healthy cohort.

The advantage of developing a cardiovascular biomarker in hair samples is that hair biomarkers can reflect average monthly exposures retrospectively (Russell et al. 2012); characteristics not possible to achieve when single timepoint blood samples or physiological measurements are collected. A related example would be the advantages offered by measuring $\mathrm{HbA} 1 \mathrm{c}$ as a longer term measure of blood glucose concentrations across the spectrum of glucose tolerance (Mels et al. 2013). Measuring levels of protein ArgMe in hair could provide a simpler, more complete overview of chronic, but dynamic, cardiovascular risk than measurements of ADMA in serum. From this standpoint, we believe that the potentially very high value of hair protein ArgMe as novel cardiovascular biomarkers justifies and deserves further investigation.

For example, the identification of specific methylation events in hair proteins can provide a basis for dedicated diagnostics kits. Our data indicate several ArgMe sites in abundant hair proteins such as keratins and histone-associated proteins (Adav et al. 2018). We favour the hypothesis that keratin- 83 is one of the major methylated proteins. This is based on (1) evidence that keratin-83 is among the most abundant proteins in the hair cuticle (Moll et al. 2008), (2) the identification of a conserved ArgMe site on keratin-83 through our proteomics data mining approach, (3) our observation that western blot signals of hair ArgMe and keratin-83 appear to overlap and (4) direct mass spectrometry analysis of keratin-83 showing at least eight ArgMe sites. The KRT83 gene encodes for a hard, type II, basic keratin-83 protein that is important in the development of hair in mammals (Liu et al. 2017), which is underscored by the fact that gene variants in KRT83 are associated with human disease (van Steensel et al. 2015). The development of antibodies specific for given keratin-83 methylation sites could accelerate future investigations of hair protein $\mathrm{ArgMe}$ as novel cardiovascular biomarkers, potentially using faster and more quantitative methods than western blots. Overall, our work contributes to an emerging field of research focused on protein ArgMe as biomarkers of disease and treatment, for example, recent investigations have proposed a novel cancer biomarker based on ArgMe of an RNA binding protein, hnRNP-A1, in blood mononuclear cells (Noto et al. 2020). It will be important to include cardiovascular patients and patients with typically high serum ADMA concentrations (e.g. kidney disease) in future investigations of hair protein ArgMe as biomarkers of CVD.

In conclusion, here we have provided evidence that the amounts of hair protein ArgMe correlate with the concentrations of serum ADMA, a well-known prognostic marker of CVD. This correlation is statistically significant in a small cohort of healthy volunteers, although it has to be acknowledged that we did not assess our participants for CVD risk (blood lipids, glucose, smoking, life history). The investigation of hair ArgMe through further basic research and clinical trials could deliver a technique to profile cardiovascular 
risk over time (including the life course) in readily available hair samples. Such samples provide a cheaper, safer, less invasive, quicker and simpler alternative to the collection of blood samples and could be collected and analysed in out-of-hospital settings. For these reasons, developing hair protein ArgMe measurements into clinically useful biomarkers could be transformational to the prevention and care of CVD, the major cause of death worldwide.

Supplementary Information The online version contains supplementary material available at https://doi.org/10.1007/s00726-021-03024-5.

Acknowledgements We acknowledge a University of Hull PhD scholarship to AM and HEIF funding to PBA, without which this work would not have been possible. We are grateful to Henry Leese (Hull York Medical School) for inspiring discussions, for help initiating the project and for comments on the manuscript. We are also grateful to the numerous students that have contributed to this project in the Beltran-Alvarez lab, including Natalie Tseu, Robert Borkowski, Faisal Nuhu, Kate Leetham, Kishmala Khan and Manjinder Dhadda, and to Kath Bulmer for outstanding technical support. The mass spectrometry analysis of keratin- 83 was performed by Adam Dowle and Tony Larson at the Centre of Excellence in Mass Spectrometry and the University of York, UK.

Funding We gratefully acknowledge a University of Hull $\mathrm{PhD}$ scholarship to AM and HEIF funding to PBA, without which this work would not have been possible.

\section{Declarations}

Conflict of interest The authors declare no competing interests.

Research involving human participants/animals This study was approved by the Hull York Medical School and the Faculty of Health Sciences Ethics Committees at the University of Hull, references 17_11 and FHS57, respectively.

Informed consent All samples were collected following informed consent.

Open Access This article is licensed under a Creative Commons Attribution 4.0 International License, which permits use, sharing, adaptation, distribution and reproduction in any medium or format, as long as you give appropriate credit to the original author(s) and the source, provide a link to the Creative Commons licence, and indicate if changes were made. The images or other third party material in this article are included in the article's Creative Commons licence, unless indicated otherwise in a credit line to the material. If material is not included in the article's Creative Commons licence and your intended use is not permitted by statutory regulation or exceeds the permitted use, you will need to obtain permission directly from the copyright holder. To view a copy of this licence, visit http://creativecommons.org/licenses/by/4.0/.

\section{References}

Adamcova M, Šimko F (2018) Multiplex biomarker approach to cardiovascular diseases. Acta Pharmacol Sin 39(7):1068-1072
Adav SS, Subbaiaih RS, Kerk SK, Lee AY, Lai HY, Ng KW, Sze SK, Schmidtchen A (2018) Studies on the proteome of human hair-identification of histones and deamidated keratins. Sci Rep $8(1): 1599$

Adeola HA, Van Wyk JC, Arowolo A, Ngwanya RM, Mkentane K, Khumalo NP (2018) Emerging diagnostic and therapeutic potentials of human hair proteomics. Proteomics Clin Appl. https://doi. org/10.1002/prca.201700048

Banjarnahor S, Rodionov RN, König J, Maas R (2020) Transport of L-arginine related cardiovascular risk markers. J Clin Med 9(12):3975

Böger RH, Bode-Böger SM, Thiele W, Junker W, Alexander K, Frölich JC (1997) Biochemical evidence for impaired nitric oxide synthesis in patients with peripheral arterial occlusive disease. Circulation 95:2068-2074

Böger RH, Sydow K, Borlak J, Thum T, Lenzen H, Schubert B, Tsikas D, Bode-Böger SM (2000) LDL cholesterol upregulates synthesis of asymmetrical dimethylarginine in human endothelial cells: involvement of S-adenosylmethionine-dependent methyltransferases. Circ Res 87(2):99-105

Bollenbach A, Huneau JF, Mariotti F, Tsikas D (2019) Asymmetric and symmetric protein arginine dimethylation: concept and postprandial effects of high-fat protein meals in healthy overweight men. Nutrients 11(7):1463

Bollenbach A, Gambaryan S, Mindukshev I, Pich A, Tsikas D (2020) GC-MS and LC MS/MS pilot studies on the guanidine (NG)dimethylation in native, asymmetrically and symmetrically NGdimethylated arginine-vasopressin peptides and proteins in human red blood cells. J Chromatogr B 1141:122024

Chen IC, Yu J (2020) Human hair: scaffold materials for regenerative medicine. Adv Exp Med Biol 1249:223-229

Chen Y, Xu X, Sheng M, Zhang X, Gu Q, Zheng Z (2009) PRMT-1 and DDAHs-induced ADMA upregulation is involved in ROS- and RAS-mediated diabetic retinopathy. Exp Eye Res 89(6):1028-1034

Craig A, Mels CMC, Schutte AE, Bollenbach A, Tsikas D, Schwedhelm E, Kruger R (2021) Urinary albumin-to-creatinine ratio is inversely related to nitric oxide synthesis in young black adults: the African-PREDICT study. Hypertens Res 44(1):71-79

Dayoub H, Rodionov RN, Lynch C, Cooke JP, Arning E, Bottiglieri T, Lentz SR, Faraci FM (2008) Overexpression of dimethylarginine dimethylaminohydrolase inhibits asymmetric dimethylarginineinduced endothelial dysfunction in the cerebral circulation. Stroke 39(1):180-184

Fleck C, Schweitzer F, Karge E, Busch M, Stein G (2003) Serum concentrations of asymmetric (ADMA) and symmetric (SDMA) dimethylarginine in patients with chronic kidney diseases. Clin Chim Acta 336(1-2):1-12

Geer EB, Islam J, Buettner C (2014) Mechanisms of glucocorticoidinduced insulin resistance: focus on adipose tissue function and lipid metabolism. Endocrinol Metab Clin North Am 43(1):75-102

Hannemann J, Appel D, Seeberger-Steinmeister M, Brüning T, Zummack J, Böger R (2020) Sequence variation in the DDAH1 gene predisposes for delayed cerebral ischemia in subarachnoidal hemorrhage. J Clin Med 9(12):3900

Hirata T, Arai Y, Yuasa S, Abe Y, Takayama M, Sasaki T, Kunitomi A, Inagaki H, Endo M, Morinaga J, Yoshimura K, Adachi T, Oike Y, Takebayashi T, Okano H, Hirose N (2020) Associations of cardiovascular biomarkers and plasma albumin with exceptional survival to the highest ages. Nat Commun 11(1):3820

Hu X, Atzler D, Xu X, Zhang P, Guo H, Lu Z, Fassett J, Schwedhelm E, Böger RH, Bache RJ, Chen Y (2011) Dimethylarginine dimethylaminohydrolase- 1 is the critical enzyme for degrading the cardiovascular risk factor asymmetrical dimethylarginine. Arterioscler Thromb Vasc Biol 31(7):1540-1546 
Iob E, Steptoe A (2019) Cardiovascular disease and hair cortisol: a novel biomarker of chronic stress. Curr Cardiol Rep 21(10):116

Jacobi J, Maas R, Cardounel AJ, Arend M, Pope AJ, Cordasic N, Heusinger-Ribeiro J, Atzler D, Strobel J, Schwedhelm E, Böger RH, Hilgers KF (2010) Dimethylarginine dimethylaminohydrolase overexpression ameliorates atherosclerosis in apolipoprotein E-deficient mice by lowering asymmetric dimethylarginine. Am J Pathol 176(5):2559-2570

Jarrold J, Davies CC (2019) PRMTs and arginine methylation: cancer's best-kept secret? Trends Mol Med 25(11):993-1009

Jarzebska N, Mangoni AA, Martens-Lobenhoffer J, Bode-Böger SM, Rodionov RN (2019) The second life of methylarginines as cardiovascular targets. Int J Mol Sci 20(18):4592

Jiang JL, Zhang XH, Li NS, Rang WQ, Feng-Ye, Hu CP, Li YJ, Deng HW. Probucol decreases asymmetrical dimethylarginine level by alternation of protein arginine methyltransferase I and dimethylarginine dimethylaminohydrolase activity. Cardiovasc Drugs Ther. 2006;20(4):281-94.

Kayacelebi AA, Langen J, Weigt-Usinger K, Chobanyan-Jürgens K, Mariotti F, Schneider JY, Rothmann S, Frölich JC, Atzler D, Choe CU, Schwedhelm E, Huneau JF, Lücke T, Tsikas D (2015) Biosynthesis of homoarginine (hArg) and asymmetric dimethylarginine (ADMA) from acutely and chronically administered free L-arginine in humans. Amino Acids 47(9):1893-1908

Krempl TK, Maas R, Sydow K, Meinertz T, Böger RH, Kähler J (2005) Elevation of asymmetric dimethylarginine in patients with unstable angina and recurrent cardiovascular events. Eur Heart J 26:1846-1851

Leiper J, Nandi M, Torondel B, Murray-Rust J, Malaki M, O’Hara B, Rossiter S, Anthony S, Madhani M, Selwood D, Smith C, Wojciak-Stothard B, Rudiger A, Stidwill R, McDonald NQ, Vallance P (2007) Disruption of methylarginine metabolism impairs vascular homeostasis. Nat Med 13(2):198-203

Leong T, Zylberstein D, Graham I, Lissner L, Ward D, Fogarty J, Bengtsson C, Björkelund C, Thelle D, Swedish-Irish-Norwegian Collaboration (2008) Asymmetric dimethylarginine independently predicts fatal and nonfatal myocardial infarction and stroke in women: 24-year follow-up of the population study of women in Gothenburg. Arterioscler Thromb Vasc Biol 28:961-967

Liu Y, Kang X, Yang W, Xie M, Zhang J, Fang M (2017) Differential expression of KRT83 regulated by the transcript factor CAP1 in Chinese Tan sheep. Gene 30(614):15-20

Manenschijn L, Schaap L, van Schoor NM, van der Pas S, Peeters GM, Lips P, Koper JW, van Rossum EF (2013) High long-term cortisol levels, measured in scalp hair, are associated with a history of cardiovascular disease. J Clin Endocrinol Metab 98:2078-2083

Mangoni AA, Tommasi S, Sotgia S, Zinellu A, Paliogiannis P, Piga M, Cauli A, Pintus G, Carru C, Erre GL (2021) Asymmetric dimethylarginine: a key player in the pathophysiology of endothelial dysfunction, vascular inflammation and atherosclerosis in rheumatoid arthritis? Curr Pharm Des. https://doi.org/10.2174/1381612827 666210106144247

Meinitzer A, Seelhorst U, Wellnitz B, Halwachs-Baumann G, Boehm BO, Winkelmann BR, März W (2007) Asymmetrical dimethylarginine independently predicts total and cardiovascular mortality in individuals with angiographic coronary artery disease (the Ludwigshafen Risk and Cardiovascular Health study). Clin Chem 53:273-283

Mels CM, Schutte AE, Schutte R, Huisman HW, Smith W, Fourie CM, Kruger R, van Rooyen JM, Malan NT, Malan L (2013) The link between vascular deterioration and branched chain amino acids in a population with high glycated haemoglobin: the SABPA study. Amino Acids 45(6):1405-1413
Moll R, Divo M, Langbein L (2008) The human keratins: biology and pathology. Histochem Cell Biol 129(6):705-733

Navone L, Speight R (2018) Understanding the dynamics of keratin weakening and hydrolysis by proteases. PLoS ONE 13(8):e0202608

Noto PB, Sikorski TW, Zappacosta F, Wagner CD, Montes de Oca R, Szapacs ME, Annan RS, Liu Y, McHugh CF, Mohammad HP, Piccoli SP, Creasy CL (2020) Identification of hnRNP-A1 as a pharmacodynamic biomarker of type I PRMT inhibition in blood and tumor tissues. Sci Rep 10(1):22155

Onwuli DO, Beltran-Alvarez P (2016) An update on transcriptional and post-translational regulation of brain voltage-gated sodium channels. Amino Acids 48(3):641-651

Onwuli DO, Rigau-Roca L, Cawthorne C, Beltran-Alvarez P (2017) Mapping arginine methylation in the human body and cardiac disease. Proteomics Clin Appl. https://doi.org/10.1002/prca.20160 0106

Pereg D, Gow R, Mosseri M, Lishner M, Rieder M, Van Uum S, Koren G (2011) Hair cortisol and the risk for acute myocardial infarction in adult men. Stress 14(1):73-81

Plott TJ, Karim N, Durbin-Johnson BP et al (2020) Age-related changes in hair shaft protein profiling and genetically variant peptides. Forensic science international. Genetics 47:102309

Post A, Bollenbach A, Bakker SJL, Tsikas D (2021) Whole-body arginine dimethylation is associated with all-cause mortality in adult renal transplant recipients. Amino Acids. https://doi.org/10.1007/ s00726-021-02965-1

Rodionov RN, Jarzebska N, Schneider A, Rexin A, Sradnick J, Brilloff S, Martens-Lobenhoffer J, Bode-Böger SM, Todorov V, Hugo C, Weiss N, Hohenstein B (2019) ADMA elevation does not exacerbate development of diabetic nephropathy in mice with streptozotocin-induced diabetes mellitus. Atheroscler Suppl 40:100-105

Roth GA, Mensah GA, Johnson CO, Addolorato G, Ammirati E, Baddour LM, Barengo NC, Beaton AZ, Benjamin EJ, Benziger CP, Bonny A, Brauer M, Brodmann M, Cahill TJ, Carapetis J, Catapano AL, Chugh SS, Cooper LT, Coresh J, Criqui M, DeCleene N, Eagle KA, Emmons-Bell S, Feigin VL, Fernández-Solà J, Fowkes G, Gakidou E, Grundy SM, He FJ, Howard G, Hu F, Inker L, Karthikeyan G, Kassebaum N, Koroshetz W, Lavie C, Lloyd-Jones D, Lu HS, Mirijello A, Temesgen AM, Mokdad A, Moran AE, Muntner P, Narula J, Neal B, Ntsekhe M, Moraesde Oliveira G, Otto C, Owolabi M, Pratt M, Rajagopalan S, Reitsma M, Ribeiro ALP, Rigotti N, Rodgers A, Sable C, Shakil S, SliwaHahnle K, Stark B, Sundström J, Timpel P, Tleyjeh IM, Valgimigli M, Vos T, Whelton PK, Yacoub M, Zuhlke L, Murray C, Fuster V, GBD-NHLBI-JACC Global Burden of Cardiovascular Diseases Writing Group (2020) Global burden of cardiovascular diseases and risk factors, 1990-2019: update from the GBD 2019 study. J Am Coll Cardiol 76(25):2982-3021

Russell E, Koren G, Rieder M, Van Uum S (2012) Hair cortisol as a biological marker of chronic stress: current status, future directions and unanswered questions. Psychoneuroendocrinology 37(5):589-601

Said MY, Bollenbach A, Minović I, van Londen M, Frenay AR, de Borst MH, van den Berg E, Kayacelebi AA, Tsikas D, van Goor H, Navis G, Bakker SJL (2019) Plasma ADMA, urinary ADMA excretion, and late mortality in renal transplant recipients. Amino Acids 51(6):913-927

Samuel SF, Barry A, Greenman J, Beltran-Alvarez P (2021) Arginine methylation: the promise of a "silver bullet" for brain tumours? Amino Acids. https://doi.org/10.1007/s00726-020-02937-x

Surdacki A, Nowicki M, Sandmann J, Tsikas D, Boeger RH, BodeBoeger SM, Kruszelnicka-Kwiatkowska O, Kokot F, Dubiel JS, Froelich JC (1999) Reduced urinary excretion of nitric oxide metabolites and increased plasma levels of asymmetric 
dimethylarginine in men with essential hypertension. J Cardiovasc Pharmacol 33:652-658

Tajti G, Papp C, Kardos L et al (2018) Positive correlation of airway resistance and serum asymmetric dimethylarginine (ADMA) in bronchial asthma patients lacking evidence for systemic inflammation. Allergy Asthma Clin Immunol 14:2

Tsikas D (2020) Urinary dimethylamine (DMA) and its precursor asymmetric dimethylarginine (ADMA) in clinical medicine, in the context of nitric oxide (NO) and beyond. J Clin Med 9(6):1843

van Steensel M, Vreeburg M, Urbina MT, López P, Morice-Picard F, van Geel M (2015) Novel KRT83 and KRT86 mutations associated with monilethrix. Exp Dermatol 24(3):222-224

vanLieshout TL, Ljubicic V (2019) The emergence of protein arginine methyltransferases in skeletal muscle and metabolic disease. Am J Physiol Endocrinol Metab 317(6):E1070-E1080

Virani SS, Alonso A, Benjamin EJ, Bittencourt MS, Callaway CW, Carson AP, Chamberlain AM, Chang AR, Cheng S, Delling FN, Djousse L, Elkind MSV, Ferguson JF, Fornage M, Khan SS, Kissela BM, Knutson KL, Kwan TW, Lackland DT, Lewis TT, Lichtman JH, Longenecker CT, Loop MS, Lutsey PL, Martin SS, Matsushita K, Moran AE, Mussolino ME, Perak AM, Rosamond WD, Roth GA, Sampson UKA, Satou GM, Schroeder EB, Shah SH, Shay CM, Spartano NL, Stokes A, Tirschwell DL, VanWagner LB, Tsao CW, American Heart Association Council on Epidemiology and Prevention Statistics Committee and Stroke Statistics Subcommittee (2020) Heart disease and stroke statistics-2020 update: a report from the American Heart Association. Circulation 141(9):e139-e596

Watts N, Amann M, Arnell N, Ayeb-Karlsson S, Beagley J, Belesova K, Boykoff M, Byass P, Cai W, Campbell-Lendrum D, Capstick S, Chambers J, Coleman S, Dalin C, Daly M, Dasandi N, Dasgupta S, Davies M, Di Napoli C, Dominguez-Salas P, Drummond P, Dubrow R, Ebi KL, Eckelman M, Ekins P, Escobar LE, Georgeson L, Golder S, Grace D, Graham H, Haggar P, Hamilton I, Hartinger S, Hess J, Hsu SC, Hughes N, Jankin Mikhaylov S, Jimenez MP, Kelman I, Kennard H, Kiesewetter G, Kinney PL, Kjellstrom T, Kniveton D, Lampard P, Lemke B, Liu Y, Liu Z, Lott M, Lowe R, Martinez-Urtaza J, Maslin M, McAllister L, McGushin A, McMichael C, Milner J, Moradi-Lakeh M, Morrissey K, Munzert
S, Murray KA, Neville T, Nilsson M, Sewe MO, Oreszczyn T, Otto M, Owfi F, Pearman O, Pencheon D, Quinn R, Rabbaniha M, Robinson E, Rocklöv J, Romanello M, Semenza JC, Sherman J, Shi L, Springmann M, Tabatabaei M, Taylor J, Triñanes J, Shumake-Guillemot J, Vu B, Wilkinson P, Winning M, Gong P, Montgomery H, Costello A (2021) The 2020 report of The Lancet countdown on health and climate change: responding to converging crises. Lancet 397(10269):129-170

Wester VL, van Rossum EF (2015) Clinical applications of cortisol measurements in hair. Eur J Endocrinol 173(4):M1-10

Whitworth JA, Williamson PM, Mangos G, Kelly JJ (2005) Cardiovascular consequences of cortisol excess. Vasc Health Risk Manag 1:291-299

Yoo JH, Lee SC (2001) Elevated levels of plasma homocyst(e)ine and asymmetric dimethylarginine in elderly patients with stroke. Atherosclerosis 158:425-430

Yoshino Y, Kohara K, Abe M, Ochi S, Mori Y, Yamashita K, Igase M, Tabara Y, Mori T, Miki T, Ueno S (2014) Missense variants of the alanine: glyoxylate aminotransferase 2 gene correlated with carotid atherosclerosis in the Japanese population. J Biol Regul Homeost Agents 28(4):605-614

Zakrzewicz D, Eickelberg O (2009) From arginine methylation to ADMA: a novel mechanism with therapeutic potential in chronic lung diseases. BMC Pulm Med 29(9):5

Zinellu A, Fois AG, Mangoni AA et al (2018) Systemic concentrations of asymmetric dimethylarginine (ADMA) in chronic obstructive pulmonary disease (COPD): state of the art. Amino Acids 50(9):1169-1176

Zurita-Lopez CI, Sandberg T, Kelly R, Clarke SG (2012) Human protein arginine methyltransferase 7 (PRMT7) is a type III enzyme forming $\omega$-NG-monomethylated arginine residues. J Biol Chem 287(11):7859-7870

Publisher's Note Springer Nature remains neutral with regard to jurisdictional claims in published maps and institutional affiliations. 